\title{
Intrahepatic Route of Administration
}

National Cancer Institute

\section{Source}

National Cancer Institute. Intrahepatic Route of Administration. NCI Thesaurus. Code C38248.

Intrahepatic route of drug administration is a method of drug delivery within the liver, predominantly via hepatic vein or artery. Regimen might be more beneficial then systemic one by delivering a higher dose of drug to the liver and reducing overall systemic exposure. 